\title{
Self-nanoemulsifying Drug Delivery System (Snedds) for Topical Delivery of Mangosteen Peels (Garcinia Mangostana L.,): Formulation Design and In vitro Studies
}

\author{
Liza Pratiwi ${ }^{*}$, Achmad Fudholi ${ }^{2}$, Ronny Martien ${ }^{2}$, Suwidjiyo Pramono ${ }^{3}$ \\ 'Department of Pharmaceutical Technology, Faculty of Medical, Tanjungpura University, Pontianak, INDONESIA. \\ 2Department of Pharmaceutics, Faculty of Pharmacy, Gadjah Mada University, Yogyakarta, INDONESIA. \\ 'Department of Pharmacy Biology, Faculty of of Pharmacy, Gadjah Mada University, Yogyakarta, INDONESIA.
}

\begin{abstract}
Objective: Purpose of this research was to get the optimum formulation of Self-Nanoemulsifying Drug Delivery System (SNEDDS) of mangosteen peels and to evaluate the permeation ability of active substances in the formulation. Method: Oil phase solubility of ethanol extract, ethyl acetate extract, ethyl acetate fraction, $n$-hexane fraction and residue of the mangosteen peels was tested with virgin coconut oil (VCO). The formulation was designed with a simplex lattice design using Design Expert software and the permeation was tested using Franz diffusion cell. Results: Based on the results of simplex lattice design methods obtained that the optimum formulation of SNEDDS was the composition of VCO, Tween 80, PEG 400 at a ratio of 1:6,95:2,05. The results of permeation test in vitro using Franz Diffusion cell indicated that the obtained SNEDDS ethyl acetate fraction of mangosteen peels that is $96.9223 \%$ higher than without preparation SNEDDS was $18,9426 \%$ on hour-8. The optimum physical evaluation SNEDDS optimum values obtained involved drug loading of $125 \mathrm{mg} / 5 \mathrm{~mL}$ SNEDDS, the transmittance value of $92 \%$, emulsification time of 65 seconds, $\mathrm{pH}$ of 6.35 , particle size $20 \mathrm{~nm}$, zeta potential $-12,40$ and stable for three months. Conclusion: SNEDDS can improve the diffusion rate of mangosteen peels as a model poorly water soluble drug.Various samples of mangosteen peels were screened as candidates for SNEDDS on the basis
\end{abstract}

of solubility of the active compound in oils, surfactants, and co-surfactants. Simplex lattice design methods can be used to obtain optimum formulation on SNEDDS.

Key words: SNEDDS, Extract, Fraction, Mangosteen Peels, Simplex Lattice Design.

Key message: Novelty in this research is the utilization of waste mangosteen peels in ethanol extract, ethyl acetate extract, ethyl acetate fraction, $\mathrm{n}$-hexane fraction and residue designed SNEDDS. SNEDDS designed with the simplex lattice design route topical are something new. Additionally, it appeared that diffusion for in vitro release from these SNEDDS.

\section{Correspondence:}

Liza Pratiwi, M.Sc, Apt, Pharmacy Department, Faculty of Medical, Tanjungpura University Pontianak, INDONESIA.

Phone: +6285643182838

Email: Iyza_pratiwi@yahoo.com

DOI: 10.5530/jyp.2017.9.68

\section{INTRODUCTION}

Premature of aging skin characterized by dry and rough skin, wrinkles and black spots has now become one of the problems feared by women, especially in the productive age. ${ }^{1}$ The peels of the mangosteen are rich in xanthone. ${ }^{2}$ From the other research found levels of mangosteen peels extract including xanthones, isoflavones, tannins and flavonoids. ${ }^{3}$ Xanthone had not dissolved in water, this limits the application system that uses water ${ }^{4}$ thus requiring a drug delivery system that can enhance penetration into the skin with a small size.

Much strategy has been used to increase the drug solubility and dissolution properties, such as the use of surfactants, water-soluble carriers, polymeric conjugates and solid dispersions. ${ }^{5}$ In recent years, the most popular approach is the incorporation of the active poorly water soluble component into inert lipid vehicles such as surfactant dispersions. ${ }^{6}$ microemulsions, ${ }^{7}$ Nanoemulsions, ${ }^{8}$ mucoadhesive, nanoparticles, ${ }^{9}$ selfemulsifying formulations, ${ }^{10}$ self-microemulsifying formulations, ${ }^{11}$ liposomes, ${ }^{12}$ nanoscale solid lipid particles, ${ }^{13}$ solid lipid nanoparticle (SLN),${ }^{14}$ and Self-Nanoemulsifying formulations. ${ }^{15}$ SNEDDS may offer an improvement in dissolution rates and extents of absorption, resulting in more reproducible blood-time profiles due to the nanometer-sized droplets present. SNEDDS can reduce the effect of $\mathrm{pH}$ variability and improve the release performance. ${ }^{16}$ Recently, the research-based focus is on the usage of natural antioxidants for obliterating the free radicals mediated skin damage. Because most antioxidant molecules are inherently unstable in nature, ${ }^{17}$ it makes them difficult to formulate in an acceptable, stable aesthetic product for cosmetic use. Further, the use of conventional delivery systems in several cases showed a little or no improvement in antioxidant profile. These observations facilitate the significance of novel delivery systems in the development of antioxidant formulations. ${ }^{18}$ Nanoemulsion made with SNEDDS allows the large scale manufacture to make so easy and economical manufacturing process that becomes the main attraction in the industry, as well as thermodynamically stable to facilitate storage. ${ }^{19}$

In the present work, we have an active substance that is the ethanol extract, ethyl acetate extract, n-hexane fraction, ethyl acetate fraction, and residue. The first test was to test extracts and fractions solubility in the oil phase. Samples with the highest solubility will be used as the active compound in this study. We developed SNEDDS using the optimum formulation applying simplex lattice design with various concentrations of oil, surfactant, and co-surfactant. Therefore, mangosteen peels specifically SNEDDS delivery systems have a potential to improve the speed of action. These studies also suggest the interesting possibility for a natural product formulated by SNEDDS. This prospect is being actively 
researched in our laboratories, with a view to developing novel drug delivery. The following in vitro release testing methods were evaluated with Franz diffusion, droplet size and size distributions were evaluated during the test period.

\section{MATERIALS AND METHODS}

The dark purple peels were selected for the study were freshly from Central Java, Indonesia. The other materials are standard a-mangostin (Sigma-Aldrich 98\%), ethanol 70\% (Dwicentra), n-hexane (Merck), ethyl acetate (Merck), methanol (Merck), aquades (Dwicentra), VCO (Bagoes), PEG 400 (Bratachem), Tween 80 (Bratachem), and buffer fosfat (Bratachem) were used.

\section{Preparation of Plant Extract}

One kg of powdered mangosteen peels was taken in five different extraction thimbles and extracted via maceration for $72 \mathrm{hrs}$ using ethanol $70 \%$, ethyl acetate. Extracted samples were evaporated using waterbath until they become thick extracts.

\section{Preparation of Plant Fraction}

Some condensed ethanol extract were partitioned with n-hexane to obtain $\mathrm{n}$-hexane soluble fractions and residues. Then, the residue was added with ethyl acetate to obtain the ethyl acetate fraction and residue. Furthermore, extracted soluble fraction of n-hexane, ethyl acetate fraction, and a residue were collected and concentrated by rotary evaporator and a waterbath at $40 \pm 0,5^{\circ} \mathrm{C}$ to obtain a thick fraction.

\section{Standard curve of a-mangosteen}

A standard curve was made by using a specific wavelength. Obtained by scanning the wavelength of the maximum wavelength in the $200-400 \mathrm{~nm}$.

\section{Verification of Analysis Method Accuracy Test}

Accuracy was determined by using a standard solution of $\alpha$-mangostin $1 \mathrm{~mL}$ in $10 \mathrm{~mL}$ of methanol. From the stock solution was a concentration of $4 \mathrm{mg} / \mathrm{mL}, 5 \mathrm{mg} / \mathrm{mL}, 6 \mathrm{mg} / \mathrm{mL}, 7 \mathrm{mg} / \mathrm{mL}$, and $8 \mathrm{mg} / \mathrm{mL}$.

\section{Precision}

Precision was determined by applying repeatability method using a-mangostin standard solution with a concentration of $5 \mathrm{mg} / \mathrm{mL}$. Precision was done by measuring the absorbance using a UV-Vis spectrophotometer 6 times repetition.

\section{Extracts and Fractions Solubility Measurements in VCO}

A total of $10 \mathrm{mg}$ of ethanol extract, ethyl acetate extract, ethyl acetate fraction, $\mathrm{n}$-hexane fraction and the residue of the mangosteen peels was added to $10 \mathrm{~mL}$ VCO as the oil phase. This mixture was conditioned in a waterbath at $40^{\circ} \mathrm{C}$ for 10 minutes. The process of dissolving the fraction in a carrier was maximized by a sonicator for 15 minutes and left for two days at room temperature. After two days, insoluble part was separated by centrifugation at $3000 \mathrm{rpm}$ for 20 minutes. Samples that were able to dissolve more of the VCO were selected sample used for subsequent optimization phase.

\section{Optimization of the formulation of the composition of surfactant, co-surfactant, and oil with Simplex Lattice Design}

Determination the optimum formulation was conducted using simplex lattice design by Design Expert software version 7. Simplex lattice design optimized the mixture of three components which are oil, surfac- tant, and co-surfactant from 14 formulations in various compositions. SNEDDS characteristic of physical properties that were used in the determination of the optimum formula is to test the transmittance and $\mathrm{pH}$.

\section{Transmittance measurements}

SNEDDS $(100 \mu \mathrm{l})$ candidate preconcentrate formula with distilled water until a final volume of $5 \mathrm{~mL}$. The mixture was homogenized with vortex for 30 seconds. Emulsions have been obtained measured absorbance at a wavelength of $650 \mathrm{~nm}$ with the blank distilled water to determine the level of clarity.

\section{pH measurements}

SNEDDS $(100 \mu \mathrm{L})$ was dissolved in $5 \mathrm{~mL}$ of distilled water. Nanoemulsion measured $\mathrm{pH}$ for optimum formula evaluation.

\section{Drug Loading measurements}

Samples selected from the mangosteen peels $(5,10,15,20,25.30,50,75$, $100,125,150 \mathrm{mg}$ ) were added to $5 \mathrm{~mL}$ SNEDDS optimal formulation. This referred to making a solid dispersion method technique. ${ }^{20}$ SNEDDS was then homogenized with a vortex for 5 minutes, with a sonicator for 5 minutes, $45^{\circ} \mathrm{C}$ waterbath for 5 minutes.

\section{Emulsification Measurement Time}

It was $500 \mathrm{~mL}$ of distilled water which was conditioned on the top stirrer at $120 \mathrm{rpm}$. A total of $1 \mathrm{~mL}$ SNEDDS optimum containing active ingredients was dripped into the media quickly.

\section{Observations of Size and Zeta Potential}

Measurings performed using a Particle Size Analyzer (PSA) were to know the size and distribution of nanoparticles. A total of $1 \mathrm{~mL}$ SNEDDS was mixed with distilled water to $5 \mathrm{~mL}$, homogenized by way of flipping over. Furthermore, it was put in a cuvette for analysis. Zeta potential measurements were performed with a Zetasizer.

\section{Observation of Stability}

SNEDDS remained heated and maintained at $37^{\circ} \mathrm{C}$ and homogenized by vortex for 30 seconds. It was observed every hour for 4 hours to determine its stability. Nanoemulsion to be stable if it did not form lumps or sediment. SNEDDS were stored for three months.

\section{Permeation Test (In Vitro)}

Diffusion test was done with in vitro using Franz Diffusion cell. The receptor compartment used phosphate buffer at $\mathrm{pH}$ 7.4. The membranes used Phyton Molurus snake skin were removable. The receptor compartment was filled with phosphate buffer $\mathrm{pH} 7.4(50 \mathrm{~mL})$ and the temperature was kept at $37^{\circ} \mathrm{C}$. Snake skin removable membrane placed between the donor compartment and the receptor compartment to the position of the stratum corneum facing upwards. Receptor solution was fed past the bottom of the membrane detachment snake skin with a peristaltic pump. Samples were taken at $0.5,1,2,3,4,5,6,7,8$ hour.

\section{Data Analysis in mangosteen peels in VCO dissolved studies}

The data was then analyzed by One Way ANOVA to compare the significant value of the dissolved extracts and fractions of mangosteen peels in the VCO. 


\section{RESULT}

\section{Standard curve, Accuracy, and Precision of a-mangostin}

Based on research obtained standard curve with the equation $y=0,0883$ $\mathrm{x}-0.0392$ with an $\mathrm{r}$ value of 0.9938 . Correlation coefficient values greater than 0.99 indicate that the analytical methods used have good linearity and can provide a response that is proportional to the concentration of the analyte in the sample. Based on the value \% recoveries obtained ranged from $92.35 \%$ to $103.41 \%$, it was in line with the terms the percentage of recovery for the analyte in the sample in the range of $80-110 \%$. RSD obtained in precision measurement was equal to $1.8008 \%$. The values obtained was quite good because the value of RSD was less than $7,3 \%{ }^{21}$

\section{Selection active compound of mangosteen peels}

Results of testing the solubility showed that the active compounds that have the VCO ability were dissolving ethyl acetate fraction. Data statistical test showed that the solubility test data of active compounds in VCO is homogeneous and normally distributed. Furthermore, in one way ANOVA test significance valued of 0,020 which means that the ability of the active compounds dissolved in the VCO varies significantly.

\section{Formulation of SNEDDS}

Formulation of SNEDDS of an isotropic mixture of oils, surfactants, and co-surfactants which can quickly establish Nanoemulsion once dispersed in the dispersing medium. The oil phase used was VCO, Tween 80 as a surfactant, and PEG 400 as co-surfactant.

\section{Transmittance}

Nanoemulsion was good to have a clear visual sighting with a transmittance of more than $90 \%$ so that the formula could be said to form a medium Nanoemulsion when it was emulsified in water. ${ }^{22}$ Based on data from transmittance and reflectance contour plot, the equation simplex lattice design was:

$$
\begin{aligned}
& \mathrm{Y}=5,11 \mathrm{~A}+9,82 \mathrm{~B}+1,59 \mathrm{C}-0,82(\mathrm{~A})(\mathrm{B})+0,07(\mathrm{~A})(\mathrm{C})+3,83(\mathrm{~B}) \\
& (\mathrm{C})-2,34(\mathrm{~A})(\mathrm{B})(\mathrm{C}) \\
& \mathrm{Y}=\text { Transmittance, A: VCO, B: Tween 80, C: PEG } 400
\end{aligned}
$$

\section{$\mathrm{pH}$}

SNEDDS $\mathrm{pH}$ testing aims to determine the safety SNEDDS especially when it is used on the skin. The $\mathrm{pH}$ value is too low to cause irritation while the ph is too high resulting in the scaly skin. The ph range of topical is $6-8{ }^{23}$ The equation of simplex lattice design for $\mathrm{pH}$ response can be seen in the following equation:

$\mathrm{Y}=0,71 \mathrm{~A}+0,73 \mathrm{~B}+0,68 \mathrm{C}-0,01(\mathrm{~A})(\mathrm{B})-0,04(\mathrm{~A})(\mathrm{C})-0,08(\mathrm{~B})(\mathrm{C})$ $+0,03(\mathrm{~A})(\mathrm{B})(\mathrm{C})$

Y: pH, A: VCO, B: Tween 80, C: PEG 400

\section{Optimum SNEDDS}

Physical characteristics test was performed on the optimum formula. The composition of VCO: Tween 80: PEG 400 ratios of 1:6,95:2,05.

\section{Drug Loading}

The test results obtained from drug loading $150 \mathrm{mg} / \mathrm{mL}$ at the optimum formula indicated that the system is not capable of dissolving fraction, that used $125 \mathrm{mg} / 5 \mathrm{~mL}$ concentration of ethyl acetate fraction of mangosteen peels.

\section{Test of Emulsification Time}

Measurements emulsification time at the optimum formula capable of forming Nanoemulsion on media distilled water for 65 seconds.

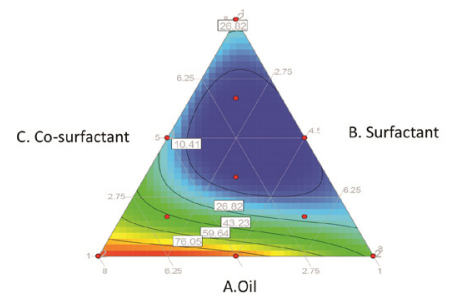

(A)

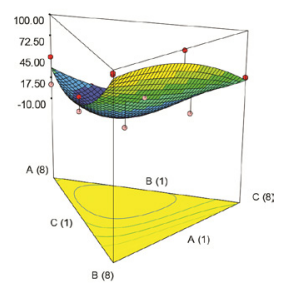

(B)
Figure 1: (A) Countor plot response of transmittance, (B) 3D Surface response of transmittance

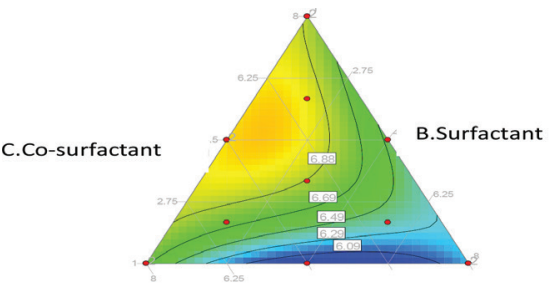

A. Oil

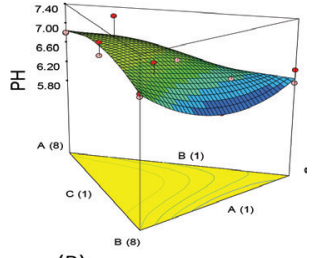

(B)
Figure 2: (A) Countor plot response of $\mathrm{pH},(\mathrm{B}) 3 \mathrm{D}$ surface response of $\mathrm{pH}$
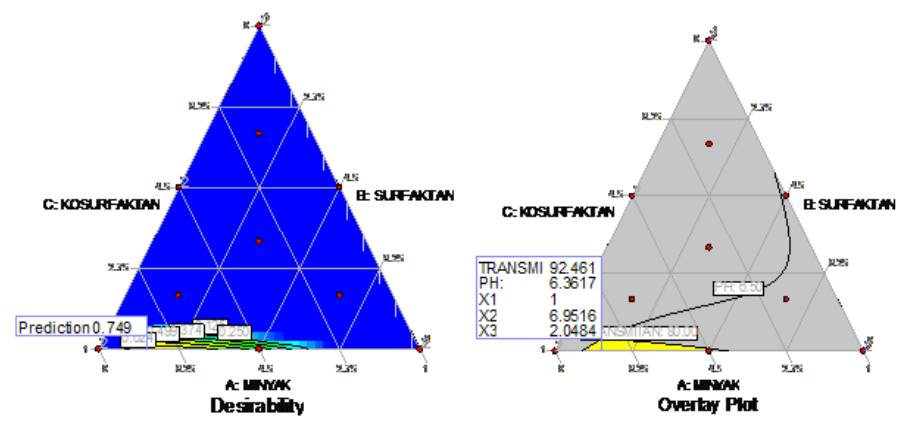

Figure 3: (A) Countor plot of desirability, (B) Countor plot of optimum formulation. (A) Desirability value 0,749 ; (B) optimum formulation from software design expert with prediction transmittance value 92,461 and $\mathrm{Ph}$ value 6,3617; X1- Oil, 1\%; X2-Surfactant, 6,9516 \%; X3-Co-surfactant, 2,0484\%;

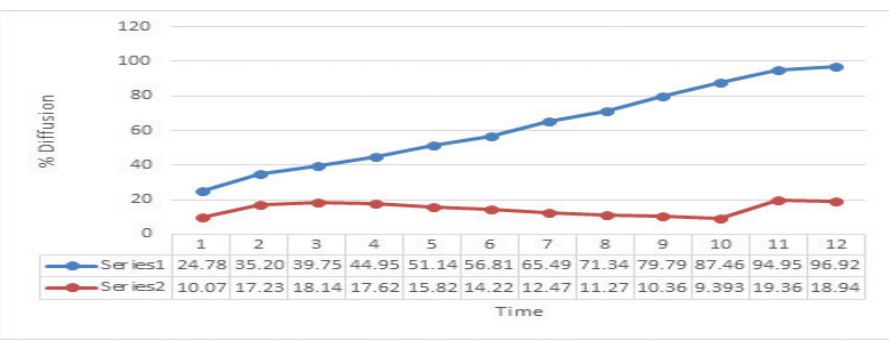

Figure 4: \% Diffusion of SNEDDS ethyl acetate fraction and ethyl acetate fraction. \% diffusion of SNEDDS ethyl acetate fraction; \% diffusion of ethyl acetate fraction (without SNEDDS formulation); Time: (1) 10 minutes, (2) 30 minutes, (3) 60 minutes, (4) 90 minutes, (5) 120 minutes, (6) 150 minutes, (7) 180 minutes, (8) 240 minutes, (9) 300 minutes, (10) 360 minutes, (11) 420 minutes, (12) 480 minutes 
Table 1: Standard curve of a-mangostin

\begin{tabular}{cc} 
Concentration $(\mathrm{ppm})$ & Absorbance \pm SD \\
\hline 3 & $0,246 \pm 0,0056$ \\
4 & $0,287 \pm 0,0134$ \\
5 & $0,395 \pm 0,0134$ \\
6 & $0,494 \pm 0,0148$ \\
7 & $0,600 \pm 0,0064$ \\
8 & $0,657 \pm 0,0007$ \\
\hline
\end{tabular}

Table 2: Results of Testing The Solubility of Active Compounds in VCO

\begin{tabular}{cc}
\hline Sample & Sample content of Compound $(\mathrm{mg} / 10 \mathrm{~mL})$ \\
\hline Ethyl acetate fraction & $7,3^{*}$ \\
Ethyl acetate extract & 6,5 \\
Ethanol extract & 6,5 \\
$n$-heksana fraction & 7,1 \\
Residue & 5,8 \\
\hline
\end{tabular}

Note: $\left.{ }^{*}\right)$ high dissolving ability

Table 3: Formulation design expert 7 version of the simplex lattice design method

\begin{tabular}{ccccccc}
\hline Std & Run & Oil & Surfactant & Co-surfactant & Transmitance (\%) & pH \\
\hline 5 & 1 & 1.00 & 4.50 & 4.50 & 98,10 & 5,94 \\
8 & 2 & 2.17 & 5.67 & 2.17 & 12,70 & 6,96 \\
3 & 3 & 4.50 & 1.00 & 4.50 & 3,80 & 6,31 \\
7 & 4 & 5.67 & 2.17 & 2.17 & 23,50 & 7,35 \\
13 & 5 & 1.00 & 1.00 & 8.00 & 41,60 & 6,19 \\
14 & 6 & 4.50 & 4.50 & 1.00 & 31,50 & 7,10 \\
6 & 7 & 1.00 & 1.00 & 8.00 & 42,70 & 6,50 \\
1 & 8 & 8.00 & 1.00 & 1.00 & 45,00 & 6,80 \\
12 & 9 & 1.00 & 8.00 & 1.00 & 94,40 & 6,66 \\
2 & 10 & 4.50 & 4.50 & 1.00 & 13,40 & 6,85 \\
4 & 11 & 1.00 & 8.00 & 1.00 & 96,40 & 6,72 \\
10 & 12 & 3.33 & 3.33 & 3.33 & 18,50 & 6,62 \\
11 & 13 & 8.00 & 1.00 & 1.00 & 8,70 & 6,82 \\
9 & 14 & 2.17 & 2.17 & 5.67 & 1,70 & 6,65 \\
\hline
\end{tabular}

Table 4: Value Diffusion SNEDDS with optimum formulation (VCO, Tween 80, PEG $400 ; 1: 6,95: 2,05$ )

\begin{tabular}{|c|c|c|c|c|c|c|}
\hline \multirow[t]{2}{*}{ Minute to- } & \multicolumn{2}{|c|}{ Levels in the formula (mg) } & \multicolumn{2}{|c|}{ Levels in the receptor compartement (mg) } & \multicolumn{2}{|c|}{ \% difussion } \\
\hline & $\begin{array}{l}\text { SNEDDS ethyl } \\
\text { acetate fraction }\end{array}$ & $\begin{array}{l}\text { ethyl acetate } \\
\text { fraction }\end{array}$ & $\begin{array}{l}\text { SNEDDS ethyl } \\
\text { acetate fraction }\end{array}$ & $\begin{array}{l}\text { ethyl acetate } \\
\text { fraction }\end{array}$ & $\begin{array}{l}\text { SNEDDS ethyl } \\
\text { acetate fraction }\end{array}$ & $\begin{array}{c}\text { ethyl acetate } \\
\text { fraction }\end{array}$ \\
\hline 10 & 1,6974 & 20,1471 & 1,6974 & 20,1471 & 24,7796 & 10,0735 \\
\hline 30 & 1,9869 & 29,4353 & 2,4112 & 34,4721 & 35,200 & 17,2360 \\
\hline 60 & 2,2262 & 27,6725 & 2,7229 & 36,2905 & 39,7504 & 18,1453 \\
\hline 90 & 2,5225 & 26,1675 & 3,0790 & 35,2401 & 44,9489 & 17,6200 \\
\hline 120 & 2,8723 & 22,8386 & 3,5029 & 31,6486 & 51,1372 & 15,8243 \\
\hline 150 & 3,1733 & 20,5403 & 3,8914 & 28,4524 & 56,8087 & 14,2262 \\
\hline 180 & 3,6927 & 17,8420 & 4,4860 & 24,9551 & 65,4890 & 12,4776 \\
\hline 240 & 3,9639 & 16,3031 & 4,8871 & 22,5419 & 71,3445 & 11,2709 \\
\hline 300 & 4,4750 & 15,0963 & 5,4659 & 20,7318 & 79,7941 & 10,3659 \\
\hline 360 & 4,8723 & 13,6047 & 5,9913 & 18,7876 & 87,4642 & 9,3938 \\
\hline 420 & 5,2859 & 34,0386 & 6,5039 & 38,7355 & 94,9474 & 19,3677 \\
\hline 480 & 5,3117 & 28,2013 & 6,6392 & 37,8852 & 96,9223 & 18,9426 \\
\hline
\end{tabular}

\section{Observations of size and droplet size distribution}

PI values were obtained from testing the size and particle size distribution was 0,30. Average size was $20 \mathrm{~nm}$. Nanoemulsion droplets resulting from this research have a zeta potential in the range of $\pm 30 \mathrm{mV}$, which is the limit value $-12,40$ able to maintain the stability of the emulsion.

\section{Observations of Nanoemulsion Stability}

Observations of Nanoemulsion stability which were performed visually indicate that Nanoemulsion remains stable, characterized by the formation of clots or sediment on Nanoemulsion.

\section{Diffusion Test of SNEDDS Preparation}

The results indicated that the obtained SNEDDS ethyl acetate fraction of mangosteen peels that is $96,9223 \%$ higher than without SNEDDS formulation was $18,9426 \%$ on hour- 8 .

\section{DISCUSSION}

Drug solubility in oil is the most important component because it is associated with the Nanoemulsion ability to keep the drug in dissolved form that is highly influenced by the drug solubility in the oil phase. Oil 
molecules which have a weak adhesion force are easier to process than the bond stretching that has stronger adhesion force. Stretching process is required to form the configuration of the oil molecules to capture molecules of the ethyl acetate fraction of mangosteen peels. As the result, the active compound molecules that interact with molecules of oil more and more make them dissolved more greatly. ${ }^{24}$ The first testing parameter to the method of simplex lattice design on this research was the value of transmittance. The clarity of emulsion can be observed by transparency, which can be measured in form of $\%$ transmittance $(\% \mathrm{~T}) .{ }^{25}$ In the equation, transmittance reveals that the interaction between the VCO and Tween 80 provide coefficient with a negative value. It shows that such interaction lowers transmittance value SNEDDS. The interactions between the VCO and Tween 80 are negative values indicate that these interactions decrease the reflectance values. Meanwhile, the interaction between VCO and PEG 400, Tween 80 and PEG 400, as well as between oil and PEG 400 increases the transmittance value. The interactions between the VCO, Tween 80 and PEG 400 are negative values indicate that these interactions decrease the reflectance values. The clearer emulsion particle size, the smaller and the most turbid emulsion particle size. The second test parameter is $\mathrm{pH}$. The value of VCO coefficient is positive. It means that the VCO can increase $\mathrm{pH}$ response. Similarly, the coefficient of tween 80 and PEG 400 increases as well, but Tween 80 coefficient is greater than VCO and VCO is greater than PEG 400. This indicates that the ability of the components Tween 80 in improving $\mathrm{pH}$ is greater than the components of VCO and PEG 400. The coefficients of interaction between VCO and tween 80 are negative, meaning that interaction of both decreases the value of $\mathrm{pH}$. Similarly, the interaction between VCO and PEG 400 also decrease the value of $\mathrm{pH}$. The interaction between VCO, Tween 80 and PEG 400 are positive indicate that these interactions increase the $\mathrm{pH}$ value. Prediction of the optimum formulation was obtained using the Design Expert software version 7. Simplex lattice design of optimization technique was applied for formulation design to minimize the formulation trials ${ }^{26}$ The area provides a prediction of the optimum formulation with the desirability of 0,749 . The optimum composition of the formula is based on analysis of the comparison of the VCO, Tween 80 and PEG 400 with the composition ratio 1: 6,95: 2,05. Emulsification time is short and it is mediated by the action of surfactant and co-surfactant that is able to quickly form a layer of oil and water interface. Co-surfactant will be tucked away and form the spaces between the surfactants so that its structure gets more bloated but has high fluidity and is capable of forming Nanoemulsion faster. ${ }^{27}$ The droplet size distribution was used as a parameter uniformity and reliability of the method of Nanoemulsion manufacture. PI value (polydispersity index) states Nanoemulsion particle homogeneity. PI value varies from 0.0 to 1.0 and a value of 0 , the more homogeneous particles. ${ }^{28}$ Nanoemulsion droplets resulting from this research have a zeta potential in the range of $\pm 30 \mathrm{mV}$. Generally, an increase of electrostatic repulsive force between Nanoemulsion droplets prevents of coalescence of droplets. On the contrary, a decrease of electrostatic repulsive forces will cause phase separation. ${ }^{29}$ In vitro test preparation used the principle of vertical type Franz Diffusion cell. Total percent of diffusion SNEDDS optimum formula for 8 hours was at 96,9223\% and without SNEDDS was 18,9426\% It shows that the ethyl acetate fraction mangosteen peels formulation with SNEDDS can increase the penetration of $\alpha$-mangostin pass through the stratum corneum.

\section{CONCLUSION}

1. The present study on SNEDDS used VCO as an oil, Tween 80 as a surfactant, and PEG 400 as a co-surfactant. The VCO solubility test shows that Fraction dissolved in ethyl acetate afford the highest.

2. Optimization of the formula with the simplex lattice design for the comparison of VCO, Tween 80 and PEG 400 was 1: 6,95: 2,05.

3. At physical evaluation, SNEDDS optimum values obtained involved drug loading of $125 \mathrm{mg}$ in $5 \mathrm{~mL}$ SNEDDS, the transmittance value of $92 \%$, emulsification time of 65 seconds, $\mathrm{pH}$ of 6,35 , particle size $20 \mathrm{~nm}$, zeta potential, and stability $-12,40$ for 3 months. In vitro permeation test of diffusion values obtained at the 8 hours was $96,9223 \%$.

\section{ACKNOWLEDGEMENT}

The authors would like to thank Faculty of Pharmacy Gadjah Mada University and Faculty of Medicine Tanjungpura University.

\section{CONFLICT OF INTEREST}

No conflict of interest associated with this work

\section{REFERENCES}

1. Swastika A, Mufrod, Purwanto. Antioxidant activity of cream dosage form of tomato extract (Solanum lycopersicum L.). Trad Med J. 2013;18(3):132-40.

2. Akao, Nakagawa Y, Linuma M, Nozawa Y. Anti-Cancer Effects of Xanthones from Pericarps of Mangosteen. IJMS. 2008;(9):355-70

3. Priya V, Jainu M, Mohan SK, Saraswati P, Gopan CS. Antimicrobial activity of pericarp extract of garcinia mangostana linn. IJPSR. 2010;1:278-81.

4. Tachaprutinun A, Meinke MC, Richter, Pan-in P, Wanicharungruang S, Knorr F, et al. Comparison of The Skin Penetration of Garcinia mangostana Extract in Particulate and Non-particulate Form. EJPB. 2014;86(2):307-13. https://doi. org/10.1016/j.ejpb.2013.12.001.

5. Chaudhari F, Trusha, Puttewar T, Patil R. Solubility enhancement of aspirin by solid dispersion method. IJPPR. 2015;5(1):208-18.

6. Vaisman L, Wagner D, Maom G. The role of surfactants in dispersion of carbon nanotubes. Adv. Colloid Interface Sci. 2006;128(130):37-46. https://doi.org/ 10.1016/j.cis.2006.11.007; PMid:17222381

7. Mandal S, Mandal SS. Microemulsion drug delivery system: A platform for improving dissolution rate of poorly water soluble drug. IJPSN. 2011;3(4):1214-9.

8. Borhade V, Pathak S, Sharma S, Patravale V. Clotrimazole Nanoemulsion for malaria chemotherapy. Part 1: Preformulation studies, formulation design and physicochemical evaluation. IJOP. 2012;431(1):138-48. https://doi.org/10.1016/j. ijpharm.2011.12.040.

9. Nair AB, Al-ghannam AA, Al-Dhubiab BE, Hasan AA. Mucoadhesive film embedded with Acyclovir loaded biopolymetric nanoparticles: in vitro studies. JYP. 2017;9(1):100-5. https://doi.org/10.5530/jyp.2017.9.19.

10. Chopade V, Chaudhari P. Development and evaluation of self-emulsifying drug delivery system for lornoxicam. IJRDPL. 2013;2(4):531-7.

11. Liu $Y$, Zhang P, Feng N, Zhang $X$, Wu S, Zhao J. Optimization and in situ intestinal absorption of self-micro emulsifying drug delivery system. IJOP. 2009;365(1):136-42.

12. Rathod S, Deshpande S. Design and evaluation of liposomal formulation of pilocarpine nitrate. IJPS. 2010;72(2):155-60. https://doi.org/10.4103/0250 474X.65014 ; PMid:20838517 PMCid:PMC2929772.

13. Kunasekaran $V$, Krishnamoorthy K. Experimenal design for the optimization of nanosale solid lipid particles containing rasagiline mesylate. JYP. 2015;7(4):28595. https://doi.org/10.5530/jyp.2015.4.2.

14. Malviya N, Somisetty K, Vemula K. Design and development of novel transmucosal patch embedded with diclofenac diethylamine loaded solid lipid nanoparticles. JYP. 2015;7(1):45-54. https://doi.org/10.5530/jyp.2015.1.8.

15. Christiansen M, Holm R, Kristensen J, Kreilgaard M, Jacobsen J, Abrahamsson B, et al. Cinnarizine food effects in beagle dogs can be avoided by administration in a self nanoemulsifying drug delivery system (SNEDDS). EUFEPS. 2014;57:164-172

16. Gupta S, Chawan S, Sawant KK. Self-nano emulsifying drug delivery system for adenofir dipivoxil: design, characterization, in vitro and ex vivo evaluation. Colloids Surf A. 2011;392(1):145-55. https://doi.org/10.1016/j.colsurfa.2011.09.048.

17. Akhila S, Bindu AR, Bindu K, Aleykutty NA. Comparative evaluation of extracts of Citrus limon Burm peel for antioxidant activity. JYP. 2015;7(4):136-40.

18. Souto E, Muller R. Nanoparticulate Drug Delivery Systems. Inform Healthc. 2007;166:213-34.

19. Amrutkar C, Salunkhe KS, Chaudhari SR. Review on Self Nanoemulsifiying Drug Delivery System. AJPTR. 2014;4:2249-3387.

20. Patel J, Kevin G, Patel A, Raval M, Sheth N. Design and development of a SelfNanoemulsifying drug delivery system for telmisartan for oral drug delivery. IJPPS. 2011;1(2):112-8. https://doi.org/10.4103/2230-973x.82431.

21. AOAC. Peer verified methods program: Manual on policies and procedures. Association of Official Analitical Chemist, Vancouver: 1993

22. Costa JA, Lucas EF, Queirós YGC, Mansur CRE. Evaluation of Nanoemulsions in the cleaning of polymeric resins. Colloids Surf A Physicochem Eng Asp. 2012;10(11):112-8. https://doi.org/10.1016/j.colsurfa.2012.10.011.

23. British Pharmacopoeia Commission. British Pharmacopoeia. London, UK. The Stationery Office: 2001.

24. Patel MJ, Patel N, Patel MA. Self-Microemulsifying Drug Delivery System 
(SNEDDS). IJPSR. 2010; 4: 29-33.

25. Rokad V, Nagda C, Nagda D. Design and evaluation of solid self-emulsifying drug delivery system of rovuvastatin calsium. JYP. 2014;6(3):37-45. https://doi. org/10.5530/jyp.2014.3.7.

26. Singhvi G, Parmar N, Patel N, Saha RN. Novel multi granules controlled release tablets of milnacipran: Design with simplex lattice, in vitro characterization and pharmacokinetic predictions. JYP. 2014;6(3):24-31. https://doi.org/10.5530/ jyp.2014.3.5.

27. Shafiq-un-Nabi S, Shakeel F, Talegaonkar S, Ali J, Baboota S, Ahuja A, et al.
Formulation development and optimization using Nanoemulsion technique: a technical note. AAPS Pharm Sci Tech. 2007;8(2):12-17. https://doi.org/10.1208/ pt0802028 ; PMid:17622106 PMCid:PMC2750368.

28. Hendriati L, Nugroho AK. The influence of oleic acid-propylene glycol mixture and iontophoresis to propranolol transdermal transport. MFI. 2009;20(4).

29. Jeevana JB, Sreelaksmi K. Design and evaluation of Self-Janoemulsifying Drug Delivery System of Flutamide. JYP. 2011;3(1):4-8. https://doi.org/10.4103/09751483.76413; PMid:21607048 PMCid:PMC3094558.

Article History: Submission Date : 04-12-16; Revised Date : 17-03-2017; Acceptance Date : 07-04-2017.

Cite this article: Pratiwi L, Fudholi A, Martien R, Pramono S. Self-nanoemulsifying Drug Delivery System (Snedds) for Topical Delivery of Mangosteen Peels (Garcinia Mangostana I.,): Formulation Design and In vitro Studies. J Young Pharm. 2017;9(3):341-6. 